\title{
Out with the old, in with the new for the European Respiratory Review
}

\author{
Sergio Harari
}

Affiliation: U.O. di Pneumologia e Terapia Semi-Intensiva Respiratoria - Servizio di Fisiopatologia Respiratoria ed Emodinamica Polmonare, Ospedale San Giuseppe-MultiMedica IRCCS, Milan, Italy.

Correspondence: Sergio Harari, U.O. di Pneumologia e Terapia Semi-Intensiva Respiratoria - Servizio di Fisiopatologia Respiratoria ed Emodinamica Polmonare, Ospedale San Giuseppe - MultiMedica IRCCS, Via San Vittore 12, Milan 20123, Italy. E-mail: sharariahotmail.it

@ERSpublications

Out with the old, in with the new: the ERR is moving to continuous publication http://ow.ly/Aago3079Jxd

Cite this article as: Harari S. Out with the old, in with the new for the European Respiratory Review. Eur Respir Rev 2017; 26: 160118 [https://doi.org/10.1183/16000617.0118-2016].

It's a new year, it's a new life for the European Respiratory Review (ERR) that sheds its skin, leaving its old format of a quarterly timetabled review to become more agile, creating a seamless and constant contact with our readers and authors: as of January 1 2017, the ERR will in fact commence publishing under a continuous model. This will lead to a decrease in the lag-time from acceptance to publication and the immediate transfer of articles to PubMed and other indexes. Each online issue will "open" at the beginning of a 3-month period and be "closed" at the end, at which point the printed version of the issue will be produced. For example, this editorial is the first article in the issue that opens in January 2017, and that will be closed and printed in March. At present, the average time from submission to first decision for manuscripts submitted to the ERR is very short ( 6 days for immediate acceptance), while major and minor revisions require, on average, 27 and 26 days, respectively. For manuscripts that are rejected the decision time is only 13 days, thus allowing authors to pursue an alternative choice very quickly. However, the old quarterly format still required fixed timing and, until recently, after a manuscript was accepted for publication it was regularly left waiting for the issue to which it was assigned: weeks and sometimes months were likely to elapse. During this period the manuscript was neither available to the authors as a publication to be cited, nor to the scientific community. But that will no longer be the case. Once accepted and edited, the paper will be made available on the ERR website (http://err.ersjournals.com), meaning it will be instantly citable and published on all major databases. This model is also being adopted for the European Respiratory Journal [1].

It's a major change that accompanies the new year; we are convinced that it will inject new dynamism into the $E R R$, further increasing its interest and visibility, factors which have already grown a lot in recent years. For example, from January to November 2016 there were 448831 visits to the website (76\% were new visits) and 698429 page views, which is a significant increase compared to 2015 (figures 1 and 2). According to the Scimago Journal and country rank [2] the ERR is among the 10 most cited journals in the respiratory field with an H-index of 34, a journal rank of 2.04 (a measure of the journal's impact, influence or prestige; the average number of weighted citations received in the selected year by the documents published in the journal during the three previous years) and a ratio of cites/documents published in the past 2 years (widely used as an impact index) of 4.85 [2]. In recent months we have

Received: Dec 092016 | Accepted after revision: Dec 132016

Conflict of interest: Disclosures can be found alongside this article at err.ersjournals.com

Provenance: Submitted article, peer reviewed.

Copyright CERS 2017. ERR articles are open access and distributed under the terms of the Creative Commons Attribution Non-Commercial Licence 4.0. 
introduced numerous innovations to the $E R R$, as I mentioned in my incoming editorial [3], and we have become even more selective (today only one-third of the papers submitted to the ERR are accepted for publication). In addition, we have had the important recognition of being accepted in the Clarivate Analytics Emerging Sources Citation Index [4], one of the world's largest databases of scientific journals. All this was made possible thanks to the great commitment of my predecessor Vincent Cottin, to whom I express my gratitude, and the excellent team work with the other European Respiratory Society journals, in particular the Editor in Chief and Deputy Editor of the European Respiratory Journal, Marc Humbert and Anh Tuan Dinh-Xuan.

FIGURE 1 Number of page views for the European Respiratory Review in the period 2012 to 2016.
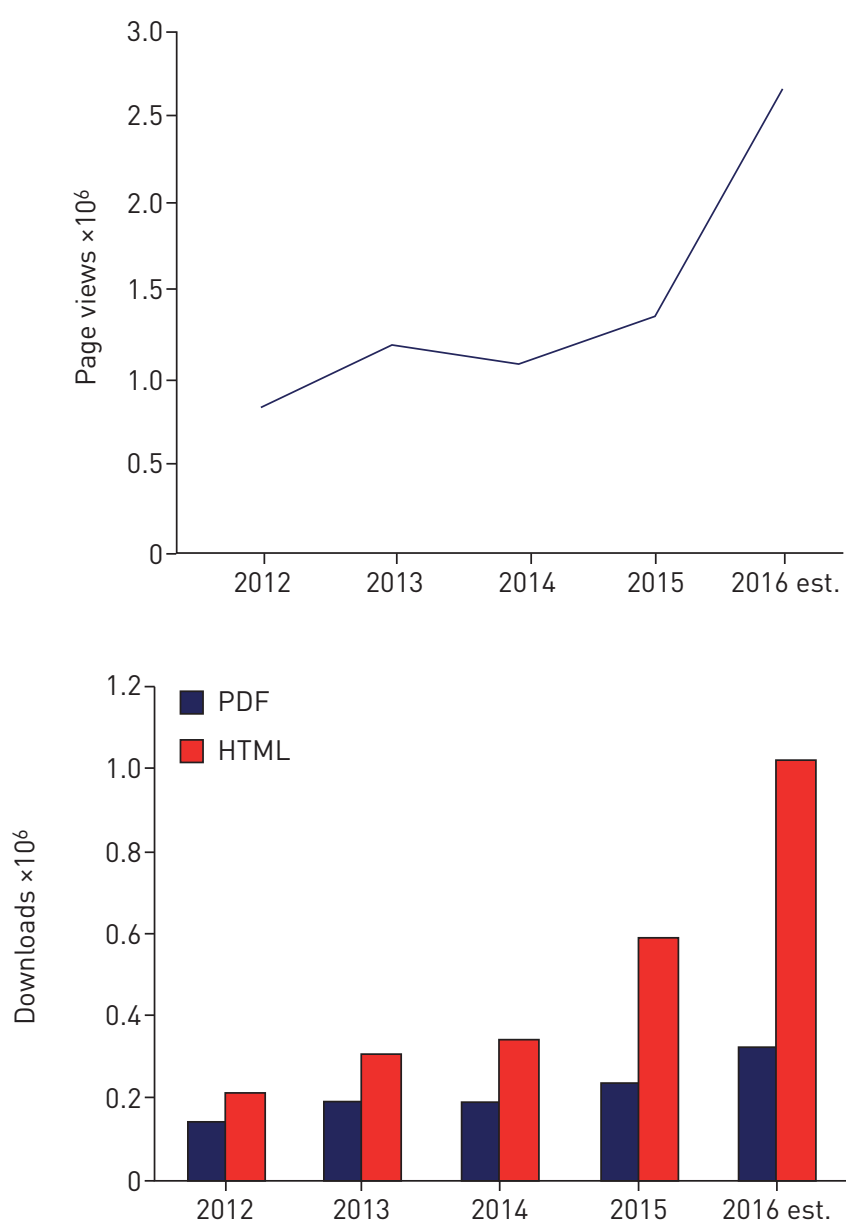

FIGURE 2 Number of downloaded PDF and HTML articles for the European Respiratory Review in the period 2012 to 2016.

From the beginning of 2017 we will hand the ERR over to you with a renewed look, with its strong legacy of consolidated successes acquired in recent years, in a new and even more agile, modern and immediately available version. As the popular saying goes, a good start is half the battle, we therefore have very ambitious goals in making it an increasingly important journal and a reference for our scientific community, we hope that this is an auspicious roll-over into the new year. We wish the best for you all for a good start.

\section{References}

1 Humbert M, Dinh-Xuan A-T, Reeves EL, et al. The ambition of the European Respiratory Journal continues: chapter 5. Eur Respir J 2017; 49: 1602393.

2 Scimago Journal and Country Rank. www.scimagojr.com/journalrank.php?category $=2740 \&$ area $=2700 \&$ type $=j \& \min =0$ \&min_type=cd Date last accessed: December 9, 2016.

3 Harari S. The goal is to go further and do better: but how? Eur Respir Rev 2016; 25: 1-3.

4 Emerging Sources Citation Index. Journal List. http://ip-science.thomsonreuters.com/cgi-bin/jrnlst/jlresults.cgi? PC=EX\&Alpha=A Date last accessed: December 9, 2016. 